\title{
Nested Leadership: The Interpretation of Organizational Change in a Multicollege System
}

Pamela L. Eddy

College of William \& Mary, pamela.eddy@wm.edu

Follow this and additional works at: https://scholarworks.wm.edu/articles

Part of the Community College Leadership Commons, Educational Leadership Commons, and the Higher Education Commons

\section{Recommended Citation}

Eddy, Pamela L., "Nested Leadership: The Interpretation of Organizational Change in a Multicollege System" (2006). Articles. 56.

https://scholarworks.wm.edu/articles/56

This Article is brought to you for free and open access by W\&M ScholarWorks. It has been accepted for inclusion in Articles by an authorized administrator of W\&M ScholarWorks. For more information, please contact scholarworks@wm.edu. 
Nested Leadership

\title{
Nested Leadership: \\ The Interpretation of Organizational Change in a Multi-College System
}

\begin{abstract}
$\underline{\text { Abstract }}$
College leaders serve important roles as guides for campus understanding during times of change. Within multi-college districts, campus members deal with several levels of leadership, ranging from department chairs to the college president to the system chancellor. These leaders may send conflicting messages regarding change or have competing end goals for change. The research reported here sought to investigate the influence of the system chancellor on change initiatives at the individual colleges within the system. Findings from this investigation concluded that leadership within the system was nested, whereby the overall direction of change came from the chancellor and was replicated as a change effort on each of the district's campuses. The implementation of the initiative, however, was filtered through the culture of each separate campus, resulting in different interpretations by campus members at each of the separate colleges. Understanding more about the filtering process that change initiatives undergo can aid in increased understanding of what makes certain changes more understood and, ultimately, more successful.
\end{abstract}

In seeking direction during times of change and uncertainly campus members look to their college president to gauge their reaction to the change process (American Council on Education, 1999). How the president frames change influences ultimate sensemaking by campus members (Kezar \& Eckel, 2001; Weick, 1995). Previous research (Kezar \& Eckel, 2001; Neumann, 1995) indicates that how the president frames organizational change sways how campus members interpret changes. When colleges are part of a multi-college district it is not only the campus 
president who has authority over institutional changes and sensemaking, but also the system chancellor.

One of every three community colleges are part of multi-campus or multi-college districts (Katsinas \& Hardy, 2004), making the impact of the system chancellor on individual campuses critical. Given the role of the system chancellor as the highest positional leader over several campuses, the question at the heart of this study was what is the influence of the system chancellor on change initiatives at the individual colleges within the system? Of particular interest was the linkage between the leadership of the chancellor and the leadership of the individual campus presidents.

\section{Literature and Theoretical Framework}

Levin (1998) argues that organizational change at community colleges is defined by adaptation to external influences and stimuli. Using a cultural lens Levin described how community college members begin to make sense of organizational change through the creation of shared meaning of experiences. Leaders serve as "sense-givers" (Thayer, 1988, p. 250, italics in original) by framing the reality for the organization whereby individuals can then react to the reality defined. In a study of sensemaking during strategic change, Gioia and Thomas (1996) determined that the leadership team's perceptions of a desirable future were key to the sensemaking process, again pointing to the role of leadership in achieving a shared understanding. Heifetz (2002) addressed the issue of leadership in times of change and posited that leaders need to provide an adaptive environment through which change is interpreted and the organizational culture altered. 
Nested Leadership

How a leader frames a situation can impact the way in which faculty and staff understand the experience and ultimately how they respond to the event of change (Fairhurst \& Sarr, 1996; Neumann, 1995). Framing by a leader involves the choice of one particular meaning over another, ultimately asserting their own interpretations over other possible interpretations to aid campus members' sensemaking. Times of change involve heightened sensemaking as campus members attempt to deal with the uncertainty emanating from new initiatives and different organizational demands.

The maturation of community colleges and the changing environment for higher education calls for different roles for community college leaders. Vaughan (1989) identified three areas of foci for the college president. These include: 1) managing the institution, 2) creating the campus climate, and 3) interpreting and communicating the institution's mission (p. 8). External changes and demands over the last decade have added complexity to the role of the community college president. In addition, administrative retirements and the hiring of replacements create opportunities for organizational change within community colleges. Weisman \& Vaughan (2001) reported $79 \%$ of community college presidents planned to retire within ten years. In 2001, 21\% of all community college presidents were new (Corrigan, 2002). Leaders' framing, therefore, provides an interpretation of change generated via these personnel changes and reactions to the external environment, ultimately impacting the sense that campus members make regarding campus activities. Framing by the campus leader thus targets campus attention in the presence of competing issues and problems facing the campus.

Given external stimuli impacting community colleges, the research question guiding this study sought to determine how, and to what end, a system chancellor framed change within a multi-college district and what was the influence of individual campus presidents on the change 
efforts. The use of descriptions of organizational change initiatives by informants, as well as, determining the source of the change initiative and the ways in which informants understood the changes, aided in answering these questions.

\section{Methodology}

The data for this qualitative case study were collected in the spring of 2003 via interviews conducted on-site at five community colleges within a district and with the system chancellor. Three interviews were conducted face-to-face at each individual campus with the college president, a member of the leadership cabinet (generally the academic vice president), and a faculty member (most often the president of the faculty senate). A total of sixteen interviews were conducted and transcribed verbatim. The district was intentionally chosen given the fact that the college presidents were all new to their campuses (less than five years). Pseudonyms were used for the names of the colleges and the individuals interviewed. Table 1 provides general background on the college presidents, their campuses, and the district chancellor.

\section{Insert Table 1}

\section{Findings}

In examining the leadership relationships between the system chancellor and the five individual campus presidents with respect to the framing of change on these campuses, it became apparent that the chancellor's leadership served as a model for the system's leaders. The specific change initiative of focus for this paper involved the change from an associate dean structure to a dean structure throughout the district system. In the fall of 2002 the new organizational structure 
Nested Leadership

was put in place, thereby reducing the number of deans and upgrading key office professionals to undertake more administrative duties formerly done by the associate deans. The goals and dictates of the chancellor regarding this initiative, however, were mediated by the embedded culture of each of the five campuses and the way in which each campus president followed through on the charge to institute the new dean structure.

\section{Nested Leadership}

The first finding from the research indicated a replication and enactment of leadership decisions on all campuses that mirrored the direction set forth by the chancellor. Similar to Russian matryoshka or "nesting dolls," the concept of nested leadership indicates the same shape and form of change on each campus as that found coming from the chancellor's office. Carrying out the metaphor of nesting dolls one can envision how each of the district campuses is contained within the larger district, with each campus representing the next level versus the campuses being contained within one another. Differences are noted, however, in how each of the districts chose to enact the district change, which is similar to how each doll within a set of matryoshka are painted uniquely, but retain the shape of the entire set of dolls.

The initiation of the change to a new dean structure started with the system chancellor. Chancellor Packer commented, "Some faculty said why did you spring this on us? I said, when we knew the only way to go was to eliminate the associate dean's positions and really say it was a new day, I was not going to take a vote." Informants commented that a change of this magnitude needed to come from the top and that the chancellor decided upon this structural change after conversations with faculty and administrative leaders on each campus. Some informants argued that the change in the organizational structure was made because of the inadequacy of some of the 
sitting assistant deans and the change allowed for an opportunity to "clean house."

Administratively, arguments for the change were based on a lack of time for leadership by the deans since much of their time was taken up with administrative duties versus providing leadership and direction to their units. The new structure promoted secretaries to take over the administrative paperwork, leaving the new deans more time for planning and leadership functions.

In designing the new structure the chancellor met with all departments on all campuses to ask questions about what was working well, what needed to be improved, and to obtain ideas for change. President Simms noted, "For several months the executive council of presidents talked about the reorganization. We knew what the chancellor wanted to do. He allowed us a lot of flexibility." In addition, the chancellor continues to meet with the district presidents on a monthly basis, as well as with representatives from the faculty senates of each campus. He seeks multiple sources of information regarding activity on each of the individual campuses and also meets with the presidents individually and visits each campus during the year. Every other year a district wide professional development conference is held for everyone employed in the district.

One of the vice presidents likened the change process to a boat. She said, "My associate deans and I got in the boat and then two people left for better positions. Two new people got into the boat. We were ready to set sail and just got off shore and the reorganization came. The way that change occurred was like waves." She was mindful of the need to aid campus members in making sense of the change given the fact that the district set an aggressive timetable to implement the new structure without providing details as to how each campus needed to reorganize. The same vice president noted of her president, "He sets the tone for wanting the campus to take care of its problems-you know, work with the people, not create big waves." 
President Simms of Don't Make Waves Community College noted, "You're going to hear about the big organizational change to a dean structure over the next few days." While all campus presidents commented on the topic of the change to the new structure, it took on varying levels of attention across the district. Some district college leaders talked less about the change in dean structure, instead focusing on change issues that were unique to their campuses. Thus, there were two tactics to leading the reorganization on the district campuses. The first involved drawing campus attention to the restructuring and identifying this change as a prime campus goal. At times, in this case, the responsibility of leading this initiative fell to the academic vice presidents since the deans were direct reports to them. The second approach to the reporting structure change involved a more indirect approach. While the mandate to change structure was dutifully carried out, some presidents chose not to use the initiative to intentionally draw employee awareness. Instead of using the new deans as a focal point of shared meaning, some presidents instead used other, more campus specific issues as the topic from which to create campus understanding.

\section{Cultural Enactment}

In implementing the new dean structure the chancellor brought in two consultants to work with the district on issues regarding organizational change. The consultants held workshops in the spring of 2002 prior to the new structure being in place and returned in the spring of 2003 for a follow up meeting. Each campus designed the change process to the dean structure independently of the others. As a result, the reaction to the new plan at each college was influenced by the ways in which each campus president presented and carried out the change. It was evident that the campus culture influenced the perception of the change. One vice president 
said, "The chancellor is certainly allowing the presidents to run their campuses. That's again why you see a different flavor in each of the campuses because they are allowed to do that." Below is an overview of the reactions of each campus and a description of the campus culture.

Tradition Bound-The oldest college in the district was tied to the traditions of the past. The arrival of a President Samson in 2000 brought a renewed sense of energy and excitement to the campus. Enrollment recently began to climb after a dip experienced as newer community colleges were built in the district and the demographics of the district began to change to include more diversity and movement to the suburbs. There is a large contingent of founding faculty on campus who carry a long institutional history and, hence, a reluctance to change. While Samson was optimistic about the organizational change, other informants discussed the lack of planning and budgetary concerns over staffing that potentially could limit the success of the reorganization. A long serving faculty noted, "The faculty feel a leadership vacuum.... lack of consistent messages from the district level." All informants on campus commented on the role of the chancellor in communications efforts within the district, indicating that the chancellor's framing, not their college president, contributed to the shared district-wide meaning of the reorganization.

Learning Centered-New cutting edge-The newest campus in the district recently opened a branch campus and was readying its main campus for a fall 2003 opening. The founding staff were formerly members of other districts within the system and exuded a sense of excitement over creating a new institution. There was an emphasis on creating a learning organization built on best practices culled from other successful institutions across the country. As one new faculty commented, "The difference here is that innovation is expected." Since the college was not open 
yet, the change in the dean structure did not require a change with past practice. Instead the new dean structure was built into the design of the new organizational structure. The vice president of students noted, "We don't just change things to change things. There needs to be a purpose in it." Staff for the new campus were cherry picked from the other four campuses, creating a sense of resentment among some of the other campus administrators who now had to struggle to fill faculty vacancies to cover the loss of experience and history. A ripple effect was felt throughout the system.

The Rogues — This college opened in 1995 and had been the youngest in the system prior to the newest campus addition in 2003. The president who opened this campus created an environment that questioned the status quo and encouraged creativity. As a result, other administrators in the district often referred to the campus as the "rogue" within the system since rules and procedures were often tested. The message sent by the chancellor with the recent hiring of a new president, Barnes, was to get the campus back in the fold with the other campuses. Campus members commented on the new cautionary attitude now in place on campus. Gone was the attitude of "take action, ask questions later." An increase in standard operating procedures also occurred with the hiring of Barnes.

Me-Toos-The second oldest college in the district had a strong faculty base and a seasoned president, Higgs, who had served as the interim president prior to being named permanent. The faculty was miffed that they did not have a larger say in how to implement the new structure, whereas the administrators commented on the need for additional resources to retool their campus to be more in line with the physical plant of the newer campuses. Higgs commented that the 
change to the new structure "was like flying a plane while building it." The president noted that his time in the military skewed his preference for use of the chain of command and the change in structure more clearly aligned the reporting structure.

Don't Make Waves-The president of this college, Simms, served years in the state central office and the district office and had an awareness of how things got done within the system. The president sought to operate within the bureaucracy to obtain the resources the campus required for growth. The faculty felt the process of moving to the new structure was not one in which they were involved. Simms, however, implemented an internal process to obtain the input into how the changes would occur on their campus.

\section{Discussion}

The influence of the chancellor on framing the organizational change to the new dean structure clearly reinforced the concept that the chancellor was the leader providing overall direction and shape for change to the district colleges. This study suggests that the historic conception of community colleges as bureaucracies (Birnbaum, 1988; Levin, 1998) still holds a strong grip over these institutions. Bureaucratic organizations rely on leadership hierarchy in their functioning. The colleges in this study followed a similar chain of command. Clearly the chancellor provided the vision and drive for change to the new reporting structure within each of the colleges. As Higgs commented, "the chancellor instigated this since he felt something was not right."

The influence of the chancellor on the hierarchy was also evident in the selection of two of the new college presidents. Lydia Simms and Richard Higgs were selected to lead their 
respective colleges by the chancellor without an open search. In the case of Simms, the president was familiar with her work within the district. He offered the presidency of the campus to her and the previous president transitioned to a position within the central district office. Higgs, on the other hand, first served as an interim president, again, hand selected by the president, with the option to make the position permanent if the interim year was successful for both parties.

How the chancellor chose to frame change was mimicked by individual campus presidents. The nesting of leadership was apparent when several of the individual college leaders used the same guiding quote regarding change offered by the chancellor, namely asking the question, "How does it benefit students?" In the case of the change under review with the organizational structure, the chancellor felt that the deans, as academic leaders, needed to devote more time to providing leadership versus fulfilling administrative functions. The hope was that the leadership by the new deans would create a better environment for the students.

While each of the colleges had the same charge for change in structure, each of the presidents approached the change in ways that were unique to them and their campus. Simms sought to communicate with campus members about the changes, but ultimately it was Simms and her vice president that made the departmental realignments for the new structure. The open search for the new deans at Don't Make Waves $C C$ resulted in the hiring of one outsider and two from within the college. Barnes was hired after the new deans were selected at Rogue $\mathrm{CC}$-none of the old deans were retained. Upon arrival at the college, Barnes held individual meetings with each campus member and also hosted public forums on campus. The president commented that he was approachable and that people felt free to say what they think - the previous president and deans were not tolerant of people speaking out. Thus, Barnes felt that the reorganization was 
successful on his campus given this change in culture that allows member freedom to express their opinions.

Given the fact that Thomas's campus was brand new, she noted, "We started with a blank page - a totally blank page." The shift to the new dean structure was a moot change since the entire campus was new. Of the 100 new staff, 50 were internal to the district-many of whom made lateral transfers to be at the new college. Innovation was a valued trait in seeking new personnel. Contrary to this experience was that of Samson, who led the oldest college in the district. Of the six new deans, three had been associate deans at the college before, two were internal to the college, and one was hired from outside the college. The vice president of instruction oversaw the 30 person committee responsible for the selection of the new deans; the faculty senate was the site of much discussion regarding the changes. Likewise for Higgs, two of the new deans were new to the college, one was internal. Informants noted a great deal of tension regarding the shift in structure. Consultants were brought in to address issues of teamwork; they noted the campus felt the decision making for the new structure was rushed and members did not feel ownership. This sentiment reinforced the concept of being the "poor second cousin" within the system.

Thus, while each campus had the same charge to move to a new dean structure, how the individual president approached the decision making for implementing and selecting the new deans was unique to their way of leading and to the culture of their campus. Underlying this issue of change was the fact that not all of the old associate deans were hired on as deans and how in turn this was interpreted on campus. 
Nested Leadership

\section{Conclusions}

Institutional culture provided the context through which sensemaking occurred in this study. The cultural context also established some initial limitations to the ways in which the presidents enacted the required change. College presidents need a sensitivity to the filtering element of culture as they undertake change on their campuses. Campuses steeped in tradition, like the campus Higgs led, may need more time to implement change as opposed to newer campuses like that led by Thomas.

Inherently, leadership on all campuses is nested via the organizational hierarchy. Thus, an implication of the findings of this study is that leaders need to consider the filtering element of institutional culture when they frame issues for campus sensemaking. The ways in which the president chooses to get out the message regarding change may therefore be influenced by this factor. For instance, on a campus with high levels of faculty involvement, it is critical to communicate change in a more involved way and to obtain buy-in from faculty leaders. If the president has a particular version of the message regarding change that they wish to be the core of the shared campus meaning, care must be given as to how others interpret the message.

Predictions of turnovers in campus leadership at community colleges bring anticipated times of change. Given the conclusions of this study, that leadership is nested on campus with the president's framing of change being echoed throughout the hierarchy, and the fact that change is filtered via the cultural context, it is important to consider how to best prepare future presidents for their roles as campus change agents. Likewise, it is critical to consider the role of campus members in change initiatives and to contemplate the role of the follower. 


\section{References}

American Council on Education. (1999). On change: Reports from the road--insights on institutional change. Washington, D.C.: American Council on Education.

Birnbaum, R. (1988). The cybernetics of academic organization and leadership. San Francisco, CA: JosseyBass Publishers.

Corrigan, M. E. (2002). The American college president, 2002 edition. Washington, D.C.: American Council on Education Center for Policy Analysis.

Fairhurst, G. T., \& Sarr, R. A. (1996). The art of framing: Managing the language of leadership. San Francisco: Jossey-Bass.

Gioia, D. A., \& Thomas, J. B. (1996). Identity, image, and issue interpretation: Sensemaking during strategic change in academia. Administrative Science Quarterly, 41(3), pp. 370403.

Katsinas, S., \& Hardy, D. E. (2004). Publicly controlled two-year institutions in the United States. Unpublished draft report, University of North Texas, Denton, TX.

Kezar, A., \& Eckel, P. (2001, April, 1001). Strategies for making new institutional sense: Key ingredients to higher education transformation. Paper presented at the American Educational Research Association, Seattle, WA.

Levin, J. S. (1998). Presidential influence, leadership succession, and multiple interpretations of organizational change. The Review of Higher Education, 21(4), 405-425.

Thayer, L. (1988). Leadership/communication: A critical review and a modest proposal. In G. M. Goldhaber \& G. A. Barnett (Eds.), Handbook of organizational communication (pp. pp. 231-263). Norwood, NJ: Ablex. 
Vaughan, G. B. (1989). Leadership transition: The community college presidency. New York: American Council on Education; MacMillan Publishing Company.

Weick, K. E. (1995). Sensemaking in organizations. Thousand Oaks, CA: Sage Publications.

Weisman, I. M., \& Vaughan, G. B. (2001). The community college president, 2001. AACC research brief. Washington, DC: American Association of Community Colleges. 
Table 1. Site Colleges and Presidents

\begin{tabular}{llccc}
\hline President* & Campus* & $\begin{array}{c}\text { Year Began } \\
\text { Current } \\
\text { Presidency }\end{array}$ & $\begin{array}{c}\text { Previous } \\
\text { Presidency }\end{array}$ & $\begin{array}{c}\text { Full Time } \\
\text { Equivalent } \\
\text { Students }\end{array}$ \\
\hline Lydia Simms & Don't Make Waves CC & 1999 & No & 7000 \\
Todd Barnes & Rogue CC & 2002 & No & 7000 \\
Debra Thomas & New Cutting Edge CC & 2000 & Yes & $3500 * *$ \\
Donald Samson & Tradition Bound CC & 2000 & Yes & 10000 \\
Richard Higgs & Me-toos CC & 2001 & Yes & $\underline{7500}$ \\
James Packer & District Chancellor & 1990 & Yes & 35000 \\
\hline
\end{tabular}

*Pseudonyms were used for president's names and college campuses.

**Branch campus opened in Fall 2002, full campus opened in Fall 2003; enrollment projections were 7000 FTE 